
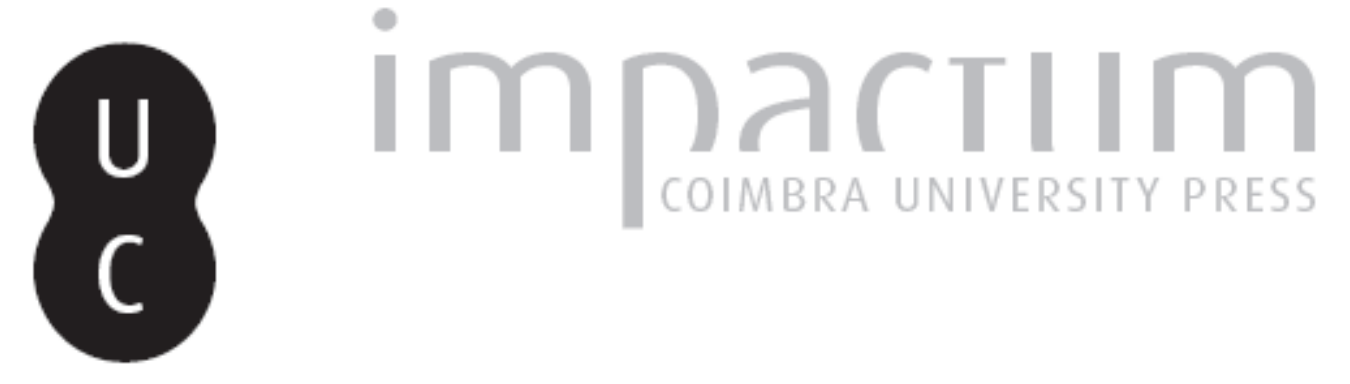

\title{
Berkeley e a realidade mental do mundo
}

\section{Autor(es): $\quad$ Farias, Vanderlei de Oliveira}
Publicado por: Universidade Católica de Petrópolis; Instituto Brasileiro de Informação em Ciência e Tecnologia

URL

persistente:

URI:http://hdl.handle.net/10316.2/33104

DOI:

DOI:http://dx.doi.org/10.14195/1984-6754_2_5

Accessed : $\quad$ 26-Apr-2023 09:40:52

A navegação consulta e descarregamento dos títulos inseridos nas Bibliotecas Digitais UC Digitalis, UC Pombalina e UC Impactum, pressupõem a aceitação plena e sem reservas dos Termos e Condições de Uso destas Bibliotecas Digitais, disponíveis em https://digitalis.uc.pt/pt-pt/termos.

Conforme exposto nos referidos Termos e Condições de Uso, o descarregamento de títulos de acesso restrito requer uma licença válida de autorização devendo o utilizador aceder ao(s) documento(s) a partir de um endereço de IP da instituição detentora da supramencionada licença.

Ao utilizador é apenas permitido o descarregamento para uso pessoal, pelo que o emprego do(s) título(s) descarregado(s) para outro fim, designadamente comercial, carece de autorização do respetivo autor ou editor da obra.

Na medida em que todas as obras da UC Digitalis se encontram protegidas pelo Código do Direito de Autor e Direitos Conexos e demais legislação aplicável, toda a cópia, parcial ou total, deste documento, nos casos em que é legalmente admitida, deverá conter ou fazer-se acompanhar por este aviso.

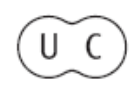



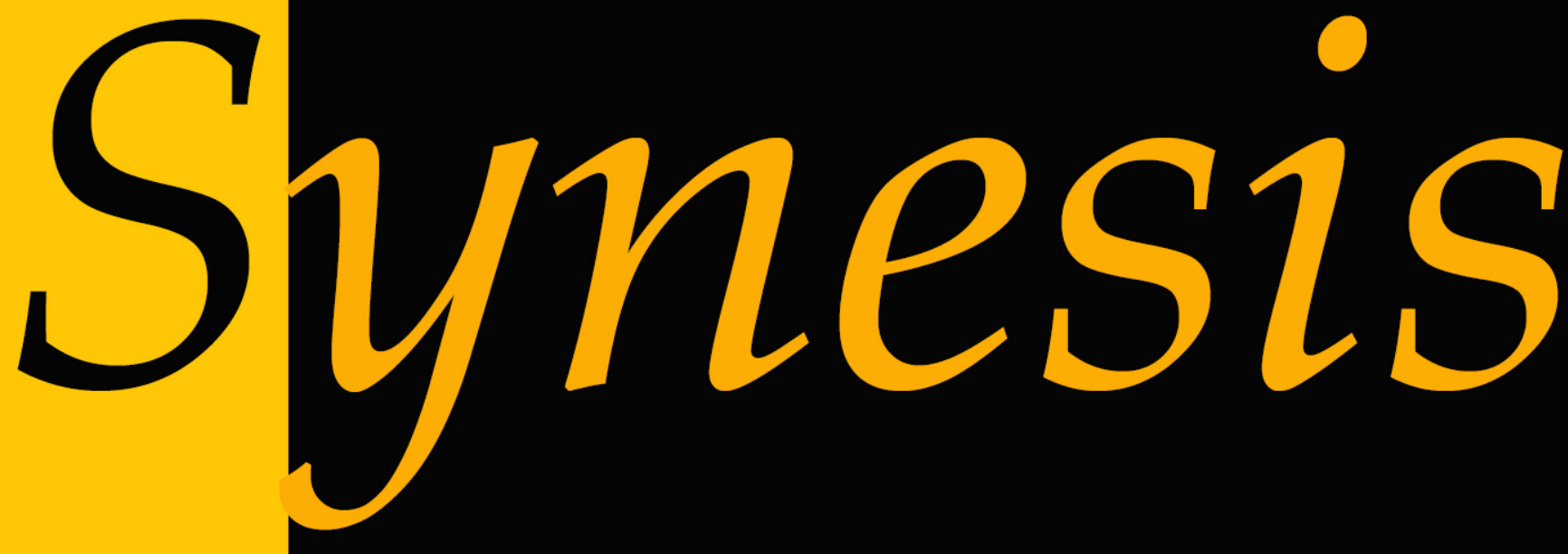

Revista do Centro de Teologia e Humanidades ISSN 1984-6754

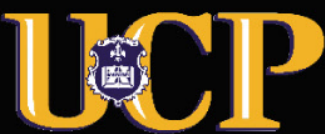




\title{
Berkeley e a Realidade Mental do Mundo
}

\author{
Vanderlei de Oliveira Farias ${ }^{1}$
}

Resumo: O principal objetivo desse texto é investigar a tese de George Berkeley de que não existe uma realidade independente da mente. Para isso, ele desenvolverá uma nova concepção de realidade, a qual por sua vez inibirá a pergunta do cético sobre a existência do mundo exterior. O imaterialismo de Berkeley será decisivo para a construção do idealismo de Kant e do conceito de vontade de Schopenhauer, além disso é inegável a sua influência nas teorias atuais da filosofia da mente.

Palavras-Chave: Realidade dependente da mente, imaterialismo, ceticismo, mundo exterior.

Abstract: The main aim of this paper is to investigate George Berkeley's thesis that there is not a mind-independent reality. For this, he will develop a new conception of reality, which in turn inhibit the skeptic's question about the existence of the outside world. The immaterialism Berkeley will be decisive for the construction of the idealism of Kant and Schopenhauer's concept of will, in addition to its undeniable influence on current theories of philosophy of mind.

Key Words: Mind-dependent reality, immaterialism, skepticism, external world.

1 Professor e Pesquisador da Faculdade Meridional (Passo Fundo/RS). Doutor em Filosofia pela Universidade de Kaiserslautern - Alemanha.

http://www.ucp.br/htmlljoomlaBR/synesis/synesis.htm 
A concepção de Berkeley de idealismo parte de uma concepção própria de realidade, a qual é melhor entendida a partir da ideia de imaterialismo. Para ele, o conceito de existência está diretamente ligado ao conceito de percepção. Levando seu argumento ao extremo ele desenvolverá um conceito específico de realidade, o qual colocará em cheque a concepção tradicional. O mundo, para ele, não tem uma realidade independente da mente, sua tese imaterialista faz o mundo desaparecer. Laptops, chicarás de chá, mesas e cadeiras não existem independentemente e fora de qualquer e toda mente. Cabe a esse texto, investigar como uma teoria tão curiosa é possível.

Berkeley denomina realidade os objetos que estão na percepção. Somente existem os dados que estão na percepção. Nos temos acesso apenas aos objetos sensíveis, os quais são diretamente percebidos pelos sentidos.

No primeiro dialogo entre Hylas e Philonous do livro Três Diálogos entre Hylas e Philonous, Philonous (o qual representa a fala de Berkeley) pergunta (Berkeley, 2005, p. 84-85):

- Será que a realidade da coisas perceptíveis consistem em ser percebida?

Ou será que está realidade é algo tão diferente de percebida e que não tem relação com mente?

A resposta de Hylas é:

- Existir é uma coisa, ser percebido é outra.

Philonous tentará durante todo o livro, através do método socrático, persuadi-lo de que uma realidade entendida como substância (substence) fora da mente, separado da percepção, não é possível. O argumento de Philonous é de que nós não podemos afirmar se um objeto externo é uma sustância material ou não.

Segundo Berkeley, "O vermelho e o azul não são cores verdadeiras" (p. 101). Cores são apenas objetos de nossa percepção. Assim sendo podemos afirmar que o idealismo de Berkeley evita falar de uma separação entre dois 
tipos de substância, a saber: uma que está em nós e outra que está fora de nós. De outro modo, ele acredita que a realidade é somente aquela que está na nossa percepção. Isso significa dizer que há uma realidade mental que contém um mundo físico.

Uma dos desafios mis importantes para Berkeley será então o de provar que a matéria fora de nós não existe. Tal prova é a base de sustentação de seu idealismo. Sua tese é de que os objetos não podem existir a não ser como algo percebido pelo intelecto.

A palavra "existir" será então usada por Berkeley sempre em relação aos dados do sentido. Tudo que existe, existe através de nossa percepção. Eu sei que meu laptop existe porque eu posso tocá-lo e vê-lo. Percebe-se aqui um afastamento de Berkeley da concepção de uma existência absoluta independente de nós. Contra o idealismo de Descartes, o qual considera laptops ideias abstratas independentes da realidade, ele afirmará que é impossível ver ou tocar algo sem nossa percepção dos objetos. Sobre a possibilidade de conhecimento dos objetos fora de nós, Berkeley nega que tenhamos a capacidade de conhecimento dos mesmos. Com isso, Berkeley apresenta uma concepção de materialismo que está intrinsecamente ligada à percepção e a sensação.

Para ele, não existe diferença entre uma ideia e uma percepção. Cor, forma, movimento e gosto não são nada mais do que ideias percebidas. Ao contrario de Descartes, Berkeley afirmará que ideias não são mais do que dados da percepção. Mais precisamente, as ideias são resultados da percepção.

Berkeley também vai fazer criticas à teoria do conhecimento de Jonh Locke. Ele é contra a diferença que o mesmo faz entre qualidades primárias e qualidades secundárias. Segundo Berkeley, as ideias não são cópias de algo fora da mente, nem mesmo objetos que existem independentes da percepção. (Berkeley, 1973, §9) Para fundamentar essa tese, Berkeley afirmará que é exatamente a separação entre qualidades primárias e secundárias que 
conduzem o pensamento ao erro. Para ele não é possível pensar que as qualidades secundárias existam independentes do sujeito conhecedor. Aos poucos, pode-se perceber a relutância de Berkeley em aceitar um dualismo de substâncias, o qual conduz muitos filósofos ao problema do ceticismo do mundo exterior. $\mathrm{O}$ mundo exterior não tem para ele o status de existente. A partir disso, ele pensa ter resolvido o problema da correspondência entre o conteúdo da mente e o conteúdo da realidade.

Berkeley muda então a concepção de matéria ou substância corporal. Para ele, tais conceitos são contraditórios.

Madeira, pedras, fogo, água, carne, ferro, e coisas parecidas, às quais dou nome e converso sobre são as coisas que conheço. Enão as teria conhecido se não as tivesse percebido através de meus sentidos; e as coisas percebidas pelos sentidos imediatamente percebidas; e as coisas imediatamente percebidas são idéias; e ideias não podem existir fora da mente; sua existência portanto consiste em serem percebidas. Quando, então, estão realmente percebidas não pode haver dúvida quanto à sua existência. (Berkeley, 2005, p. 153)

Os objetos da percepção constituem o critério de Berkeley para determinação daquilo que existe. Os objetos do mundo exterior são, na verdade, objetos de nossa percepção. Segundo ele, não existe um ser absoluto em si fora da mente.

Se nós temos somente acesso aos objetos da percepção, então nós deveríamos nos perguntar, qual é a causa das sensações que chegam até nossos sentidos. Para Berkeley, a causa não é nenhuma qualidade, ou ideia, ou ligação de ideias. Não existe nenhum corpo ou substância material. O que se pode afirmar, segundo ele, é que a causa das ideias só pode ser uma substância imaterial ou mental. 


\section{O PROBLEMA DO REALISMO}

Berkeley irá defender um tipo específico de empirismo que nega a necessidade de se assumir o realismo do mundo exterior. Pois, é exatamente, na sua opinião, o realismo que nos conduz ao materialismo e, conseqüentemente ao problema do ceticismo. Embora Berkeley seja um empirista, ele vê uma incompatibilidade entre realismo e empirismo. O seu ponto de partida será a percepção e, ao invés de pressupor a existência de uma realidade independente de nós, ele encontrará na tese imaterialista a base de seu idealismo empírico.

O problema do materialismo estaria no fato de pressupor a existência de algo independente do sujeito conhecedor. Para ele, a existência da matéria é algo contraditório, pois é incompatível que haja uma noção consistente sobre ela.

[ ] não tenho razão para acreditar a existência da matéria. Não tenho nenhuma intuição imediata sobre ela, nem posso inferir imediatamente através de minhas sensações, ideias, noções, ações ou paixões, uma substância irracional, não-perceptiva e inativa - seja por dedução provável ou conseqüência necessária. Enquanto que a existência do meu eu, ou seja minha própria alma, mente o princípio racional, eu evidentemente conheço por reflexão. ( Berkeley, 2005, p.156)

Desde o primeiro Diálogo, Philonous tem uma argumentação conseqüente contra a possibilidade de algo existindo fora da mente, acompanhe a seguinte parte do diálogo:

Philonous - [ ] Se você puder conceber ser possível, para qualquer mistura ou combinação de qualidades ou de qualquer objeto perceptível, existir sem a mente, então eu vou considerar isso realmente possível.

Hylas - [ ] O que pode ser mais fácil do que conceber uma árvore ou uma casa existindo por si só, independente e desapercebida

http://www.ucp.br/html/joomlaBR/synesis/synesis.htm 
de qualquer mente? Eu concebo, agora, sua existência desta maneira.

Philonous - Você diria, Hylas, que pode ver uma coisa que é, ao mesmo tempo, invisível?

Hylas - Não isto seria uma contradição.

Philonous - Não é uma contradição idêntica falar sobre "conceber" uma coisa que é "inconcebível"?

Hylas - É

Philonous - A àrvore ou casa sobre a qual você pensa é concebida por você?

Hylas - Como pode ser diferente?

Philonous - E o que é concebido está seguramente na mente?

Hilas- Sem dúvida, aquilo que é concebido está na mente?

Philonous- Como pôde então dizer que você concebeu uma casa ou àrvore existente independentemente e fora de qualquer e toda mente?

Tal tese de Berkeley, descrita nas palavras de Philonous, resume a sua convicção de que não pode haver qualquer coisa material e perceptível existindo senão unicamente na mente. Esse argumento é uma clara refutação à tese do realismo. Para ele é impossível pensar que temos acesso a objetos físicos sem a mediação da percepção. Somente temos conhecimento da existência de objetos na percepção.

Para Berkeley a concepção de realismo de Locke tem sua origem no desenvolvimento da sua denominada teoria da abstração. Ao separar os objetos da sensação ou percepção, Berkeley cria um dualismo ontológico, de um lado a realidade física do mundo, de outro os dados da percepção.

Essa teoria da percepçãoafirma a diferença entrequalidades primárias e secundárias, diferença essa que Berkeley nega. Fundamentalmente, ele nega a estrutura que estabelece a separação entre o mundo que está em nós, e aquele que está fora de nós. Mais do que denunciar um problema da filosofia teórica de Locke, Berkeley identifica uma contradição presente nas teorias de toda uma tradição, para citar alguns: Aristóteles, Hobbes, Descartes e Locke, além de toda a física newtoniana. 
Para Berkeley, o conceito de substância somente pode ser aceito quando se refere às propriedades ou estados da sensação. Para esse autor, não há sentido algum falar em uma substância material existindo independente da sensação. Da mesma forma, ele irá negar a possibilidade de uma teoria da correspondência: Mesmo se fosse possível, que ideias correspondessem com corpos fora da mente, como seria possível reconhecer tal correspondência? Pergunta ele no parágrafo 18 do Tratado sobre os Princípios do Conhecimento Humano.

Berkeley conhecia o problema do ceticismo sobre a existência do mundo exterior. Ao modificar a concepção de matéria da tradição e ao negar o realismo em defesa da tese do imaterialismo, ele está evitando um dos maiores desafios da teoria do conhecimento da filosofia moderna, a saber, o ceticismo.

\section{O DESAFIO CÉTICO}

Uma teoria que se propõe a falar sobre a existência mental do mundo exterior pressupõe uma concepção do que é matéria. Berkeley nega que uma teoria sobre a existência do mundo exterior deva ser obrigatoriamente fundamentada num realismo do tipo metafísico. Para isso, ele não aceita uma diferenciação entre os objetos da percepção e os objetos que são independentes da mente.

O autor refuta o conceito de substância enquanto matéria existindo fora de nós, pois é exatamente tal concepção que nos conduz ao problema do ceticismo sobre a existência do mundo exterior. O cético não acredita que exista uma ponte segura entre o mundo das percepções e o mundo em si fora de nós. Para ele, essa correspondência é impossível. Segundo Berkeley tal problema será solucionado somente a partir de uma nova concepção de realidade a qual pressupõe outra concepção de matéria, que 
conseqüentemente evitará o problema do ceticismo do mundo exterior.

Berkeley desenvolve no primeiro dialogo do livro: Três Diálogos entre Hylas e Philonous uma clara argumentação contra o cético. O debate começa com a não aceitação de Philonous da tese de Hylas de que existe um mundo material. Para Philonous tal tese conduz necessariamente ao ceticismo. A aceitação da existência de uma causa material existindo independente de nós abrirá a possibilidade para dúvida cética. Hylas defende, de outro modo, a existência de objetos físicos no mundo. Tal existência leva a pergunta de Philonous sobre a natureza das coisas que existem independente dos sentidos.

Berkeley não nega a existência de um mundo físico, mais importante do que isso ele põe em questão se o ser da matéria está no mundo material. A tese que será defendida por Philonous é de que se dermos ao conceito de realidade o status de algo que existe independente da percepção, então não será possível refutar a dúvida cética sobre a existência do mundo exterior. Isso levará Philonous a mudar a concepção de Hylas sobre o estatuto das coisas perceptíveis:

Philonous: - O que você quer dizer com "Coisas Perceptíveis"? Hylas: - Aquelas coisas que perceptíveis através dos sentidos. Você acha que eu quis dizer outra coisa?

[...] Philonous: - Parece-me que então, por "coisas perceptíveis" entende-se somente aquilo que pode ser percebido imediatamente pelos sentidos? (Berkeley, 2005, p.84)

O que se percebe no texto é uma relutância de Hylas em aceitar que não existe uma diferença entre "existir" e "ser percebido". Para ele, embora as coisas são percebidas através dos sentidos, elas existem de uma forma distinta fora da mente. Trata-se da matéria. Hylas defende a opinião dos filósofos os quais entendem que a matéria existe independente dos nossos sentidos. A tarefa de Philonous é dissuadí-lo de tal tese.

Berkeley defenderá uma espécie de monismo, onde há uma 
identificação entre o conteúdo da percepção é aquilo que existe. Somente existe aquilo que está na percepção. Existir é ser percebido. Esse est percipi.

A gênese do ceticismo reside exatamente na não observância da necessidade de um monismo. Com o dualismo tem-se, então, o seguinte paradoxo: embora nós nos esforcemos por um conhecimento seguro da realidade, nunca poderemos saber a verdadeira natureza de uma coisa. A opção pelo dualismo ignora tal paradoxo. Para Berkeley, a realidade que existe independente de nós sempre permanecerá escondida.

Para escapar do problema do ceticismo sobre a existência do mundo exterior, Berkeley evita cair na cilada de tentar responder o problema da correspondência entre a realidade e a mente. Sua tese será então de que nossas representações mentais têm como fonte somente os objetos que estão na nossa percepção. Uma árvore não tem existência fora da mente.

Que não há nenhuma substância na qual ideias possam existir além do espírito, isso parece evidente para mim. Eque os objetos imediatamente percebidos são ideias, todos concordamos. Eque qualidades perceptíveis são objetos imediatamente percebidos ninguém pode negar. Está, portanto, claro que não pode haver nenhum "substrato" de tais qualidades além do espírito, no qual existem, sem que seja através de modo ou portanto, que exista qualquer "substrato irracional" dos objetos dos sentidos e, "nessa aceitação", que exista qualquer substância material (Berkeley, 2005, p. 161)

Hylas defende, de outro modo, uma concepção de matéria que existe independente de nossa percepção. Não é de forma impensada que o opositor de Philonous tenha esse nome. A palavra Hylas está no vocabulário técnico de Aristóteles e era usado para conceituar a matéria-prima em oposição à forma, ou coisas naturais. A intenção de Berkeley é claramente fazer uma ironia com aqueles que ele denomina materialistas. Um materialista, a partir da filosofia de Berkeley, pode ser então entendido como todo aquele que aceita que a matéria existe independente de nossa consciência.

http://www.ucp.br/html/joomlaBR/synesis/synesis.htm 
Ao final do primeiro diálogo, Hylas é levado a aceitar que não é possível "conceber ou entender como qualquer coisa diferente de uma ideia pode ser igual a uma ideia. Nenhuma ideia pode existir sem a mente". (Berkeley, 2005, p. 125) Com a concordância de Hylas, Berkeley pretende demonstrar também que a pergunta cética foi superada. Ao negar a possibilidade de uma realidade existindo independente da percepção, ele nega a pergunta do cético sobre uma correspondência segura entre a mente e os objetos que existem independentes de nós. Depois de ter negado o realismo, cabe agora a Berkeley a tarefa de demonstrar a viabilidade da tese do imaterialismo, a qual será o oposto da tese materialista.

\section{O IMATERIALISMO E A REALIDADE MENTAL DO MUNDO}

Com a tese do imaterialismo, Berkeley objetiva superar a tese do realismo. A tese do imaterialismo tem como base o argumento de que os objetos da percepção não existem independentes da mente. Nossa percepção de uma árvore irá mudar dependendo das mudanças que ocorrerem em nossos órgãos de percepção. Não é possível perceber as características de uma matéria existindo fora da mente.

O idealismo de Berkeley fundamenta-se em dois grandes princípios: $1^{\circ}$ ) ele aceita somente a existência da mente e a existência de objetos sensíveis; e, $2^{\circ}$ ) ele toma essas existências como inseparáveis. Disso podemos derivar que os objetos da percepção são dependentes da mente para existir. Não existe mais uma diferença entre os objetos da percepção e os objetos de nossa representação mental. Mente e percepção formam juntas nossas representações do mundo. Toda percepção é uma representação. Conseqüentemente nós só podemos ter acesso às representações e não as qualidades reais das coisas ou dos objetos. Somente existe aquilo que pode ser percebido.

O imaterialismo de Berkeley apresenta uma nova compreensão 
de realidade, a qual nega possibilidade da existência da matéria fora da mente. A realidade refere-se somente aquilo que é percebido. A qualquer outra realidade não temos qualquer tipo de acesso. Tal posição representa a negação da concepção clássica de realismo.

De outra forma, o realista parte do pressuposto de que os objetos são reais porque existem independente de nós. O maior representante dessa concepção é, sem dúvida, Descartes o qual busca no argumento das ideias inatas uma forma de correspondência com o mundo que está fora de nós. As ideias inatas são a garantia de uma correspondência segura com o mundo exterior.

O único tipo de realidade que Berkeley irá aceitar é um realismo da percepção. Enquanto Descartes nega que a percepção seja uma fonte segura para o conhecimento, Berkeley encontrará nela a única fonte do conhecimento. Da mesma forma John Locke pode ser considerado um realista, pois também acreditava que a matéria existia independente de nossa percepção. O imaterialismo é a alternativa criada por Berkeley para moldar o status da matéria.

No segundo dialogo da obra Três Diálogos entre Hylas e Philonous, Philonous tenta persuadir Hylas de que a matéria é uma palavra vazia. Embora Hylas concorde que o acesso ao ser da matéria é improvável, ele porém não aceita que ela seja impossível. Ele argumentará contra Philonous que a matéria não pode existir independente da mente.

Para Hylas, a matéria existe em um sentido abstrato e indeterminado. Ele não consegue deixar de supor que exista matéria, mesmo que lhe seja difícil determinar a sua natureza. Ele não está satisfeito com a resposta de Philonous de que é impossível a existência da matéria independente de nós. Philonous tenta responder a difícil pergunta de Hylas a partir de um argumento negativo. Se a matéria tem um sentido indeterminado nós não podemos ter uma compreensão sobre ela. Não pode haver um significado de matéria que é obscuro e indefinido, definição admitida por Hylas e, que 
possa ser percebido.

Para Philonous,

[ ] somente se pode inferir a existência de uma coisa a partir de uma causa, efeito, sinal ou outra circunstancia, mas onde não há nada disso, onde nenhuma razão ou revelação nos induz acreditar na existência de alguma coisa, onde nós não temos ao menos uma relativa noção dela, onde uma abstração é feita entre perceber e ser percebido, entre espírito e ideia, e por fim, onde somente existe a mias inadequada e vaga ideia, e eu realmente não vou concluir contra a realidade de qualquer noção, ou existência de qualquer coisa, vou sim deduzir que você não quer dizer nada, que você faz uso das palavras sem sujeito ou propósito sem qualquer desígnio ou significado que seja. (Berkeley, 2005, p. 125)

Oimaterialismo de Berkeley éconseqüenteem seus mínimos detalhes. Ao notar a inconsistência da argumentação de seus colegas empiristas e da argumentação metafísica de Descartes, ele investe em seu projeto de criar uma nova concepção de realidade, contra a tese de que existiria matéria fora de nossa mente. A percepção passa a ser então o critério para determinar a existência dos objetos no mundo. Com isso, o mundo, a realidade passa a ter uma realidade puramente mental. Tal monismo inibe a possibilidade de que o cético tenha sucesso na sua empreitada contra o conhecimento. Ao dar à realidade um status mental, Berkeley desenvolve com seu imaterialismo, um idealismo empírico que influenciará fortemente a filosofia teórica moderna, principalmente a obra Crítica da Razão Pura de Immanuel Kant e a obra $O$ mundo como vontade e como representação de Arthur Schopenhauer. As teoria atuais da filosofia da mente, da mesma forma, encontram em sua obra inspiração para o entendimento da realidade da mente e do cérebro. 


\section{Referências bibliográficas}

ALLAIRE B. Erwin. Berkeley's Idealism,in: Creery, Walter (Hrsg.) Matter and the external world, mind and notions. London (u.a): Routledge, 1991. Vol. III George Berkeley.

ALLISON, Henry E. Kant's Critique of Berkeley, in: Journal of the History of Philosophy 11 (1973), S.43-63.

AUNE, Bruce. Knowledge of the external world. Routledge. London. 1990.

BENNETT, J. Locke, Berkeley, Hume: Central Themes. Oxford: Oxford University Press, 1971.

BENNETT, Jonathan. Substance, Reality and Primary Qualities in Creery, Walter (Hrg.) Matter and the external world, mind and notions. London (u.a): Routledge, 1991. Vol. III George Berkeley.

BERKELEY, G. Philosophical Works. Dent. London. 1975.

BERKELEY, G. Três diálogos entre Hylas e Philonous. São Paulo: Icone, 2005

BERKELEY, G. Tratado sobre os princípios do conhecimento humano. São Paulo: Abril Cultural, 1973.

BERMAN, D. George Berkeley: idealism and the man. Oxford: Cla-rendon Press, 1994.

BERMAN, David. George Berkeley. In. Brown, Stuart. (org.) Britisch Philosophy and the Age of Enlightenment. Vol. V. Routledge. London. 1996.

BRACKEN, H. M. “Berkeleys's Realisms". The Philosophical Quar-terly, v. 8, n. 30, p. 41-53, 1958.

BRYKMAN, G. Berkeley et le voile des mots. Paris: Vrin, 1993.

DANCY, Jonathan. Berkeley an Introdution. Basil Blackwell. 1987.

DONEY, W. “Berkeley's argument against abstract ideas", Midwest Studies in 
Philosophy 8 (1983) 295-308.

FILHO, Raul Landin. Descartes: „Idealista empírico erealista transcendental”? in: Síntese Nova Fase, 24 n 74. 1996.

FLAGE, D. E. Berkeley's Doctrine of Notions. London/Sydney: Croom Helm, 1987.

FOGELIN, R. J. “The Intuitive Basis of Berkeley's Immaterialism”. History of Philosophy Quartely, v. 13, n. 3, p. 331-344, 1996.

HALBFASS, Wilhelm. Descartes' Frage nach der Existenz der Welt. Anton Hain. Meisenheim am Glan. 1968.

JESSOP, T. E. (ed.). Berkeley: Philosophical Writings. Austin, 1953.

JUSTIN, Gal. D. On Kant's Analysis of Berkeley, in: Kant Studien. 65 (1974). S. 20-32.

LUCE, A. A. Berkeley's Immaterialism. London: Thomas Nelson and Sons, 1945.

LUCE, Arthur A. (Hrg.). The works of George Berkeley, Bischop of Cloyne. Bibliotheca Britannica Philosophica. 1979.

MONTAGUE, W. P. “The New Realism and the Old”. Journal of Philosophy, IX, p. 39-46, 1912.

POPKIN, R. H. “Berkeley and Pyrrhonism". In: M. Burnyeat (ed.). The Skeptical Tradition. Berkeley/Los Angeles/London: Uni-versity of California Press, 1983.

PRICHARD, H.A. Knowledge and Perception. Clarendon Press. Oxford. 1950.

SCHUMACHER, Ralph. Kant und Berkeley über die Idealität des Raumes. In: V. Gerhardt, R.-P. Horstmann, R. Schumacher (Hg): Akten des IX. Internationalen Kant-Kongresses. Berlin/New York 2001.Walter de Gruyter, Bd. II, S. 238-248. 
SMITH, P. “As Respostas de Berkeley ao Ceticismo". Doispontos, v.1, n.2, p. 35-55, 2005.

TIPTON, I. C. Berkeley: The Philosophy of Immaterialism. London: Methuen, 1974.

URMSON, J. O. Berkeley. Oxford: Oxford University Press, 1982.

WINKLER, K. P. Berkeley: An interpretation. Oxford: Oxford Press, 1989.

WOODBRIDGE, J. E. “Berkeley's Realism". Studies in the History of Ideas, I, p. 188-215, 1918. 